\title{
Plant: a Necessity of Life
}

\section{Abubakar Bello Usman, Salisu Abubakar, Chinweoma Alaku, Ogechi Nnadi}

\author{
Biotechnology and Genetic Engineering Advanced Laboratory, \\ Sheda Science and Technology Complex, P. M. B. 186, Garki, Abuja-FCT, Nigeria
}

\begin{abstract}
Plant is one of the major forms of life on earth. It can produce its own food but cannot move about. Plants have well organized structures. They are beautiful and they determine local climates and are used as live fences. They phytoremediate and cool our environment. They provide us with oxygen, medicines, fuel, timber, recreation, industrial products; preservatives, pesticides in addition to all the three necessities of life: food, clothing and shelter. They purify the air and water bodies. It is therefore impossible to talk about life without plants because of their importance to the balance of nature. However, people have altered and often degraded their environment, though it has been taking place so gradually that its effects have not been drastically felt. Despite the enormous benefits of plants to humanity, they are disappearing at alarming rates. The reasons for this loss are many and include many anthropogenic activities. It is therefore quite imperative to ensure their effective conservation. This paper summarizes available information about the direct and the indirect benefits of plants and suggests some important measures to ensure their posterity. I hope, by bringing this information together, people will appreciate our plants and be frugal in using them.
\end{abstract}

Keywords: plants; benefits; humanity; society; environment

\section{INTRODUCTION}

According to the Oxford Advanced Learner's Dictionary (2006 Edition), a plant is a living thing that grows in the earth and usually has stem, leaves and roots. In other words, the term plant refers to a living thing that usually can produce its own food, reproduce, but cannot move around. These include trees, shrubs, herbs and vines. The basic plant structure comprises two major organ systems these are shoot system and the root system. The shoot system is made up of those parts of the plant normally found above the ground such as leaves, buds, branches and stems. In flowering plants, flowers and fruits are also part of the shoot. The root system comprises those parts of the plant normally found below the ground; these include roots, tubers, and rhizomes.

Plant is one of the major kingdoms of life forms, a life form we cannot live without because Plants are the only life forms that can produce their own food (upon which we depend). They have a wide spectrum of uses (Figure 1). 


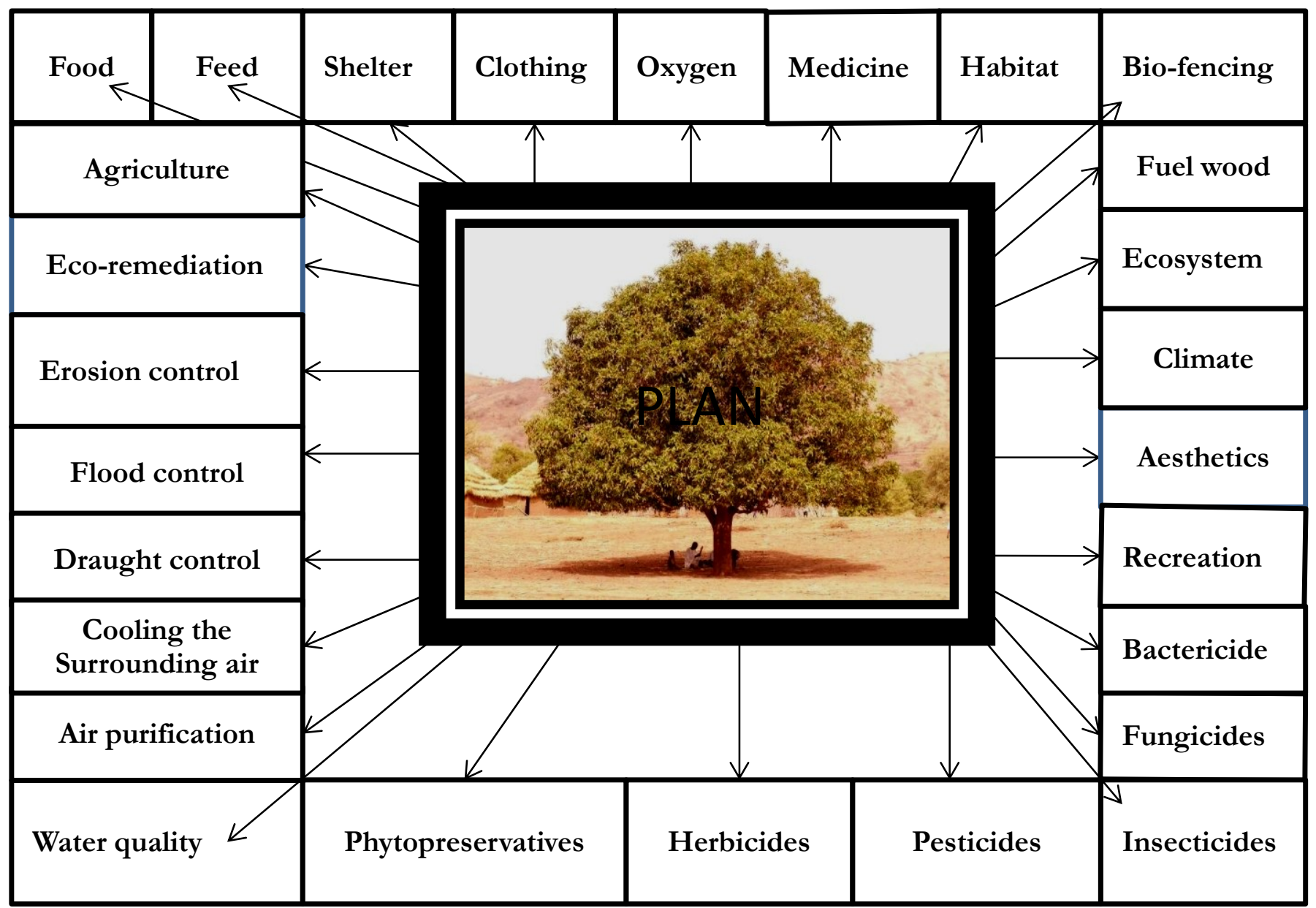

Figure 1. Role of plants in the society.

\section{PLANT AND ITS BENEFITS TO THE SOCIETY}

Plants and plant communities are very important to humans and their environment as shown below:

\section{Food}

Plants are the primary source of foodstuff for human populations. Many cereals, legumes, roots and tubers, fruits, nuts, leaves, and young shoots of plants provide valuable and fundamental diets for human consumption and well being. Furthermore, many plant species are widely utilized as spices and condiments which have strong flavor, taste and smell as well as nutritional and medicinal importance, e.g Zingiber officinale, Capsicum frutescens, Solanum nigrum, Piper nigrum, Parkia clappertonia, Xylopia aethiopica, Prosopis africana and Adansonia digitata (Kayode et al., 2008 and Oparaeke et al., 2004).

\section{Feed}

Plants are a source of foodstuff for livestock including wildlife populations. Most feeds are produced from crops at the farm and consumed by the animals some time later. However, 
some straight feeds and particularly mixed feeds are also produced from plant materials and sold by feed mills. Feed raw materials often include among others: cereals and their byproducts; oilseed by-products; leguminous seeds; roots and tubers; green crops/pasture; silages; hays; and straws.

\section{Shelter}

Plants are made into materials used to build both the exterior and interior of different kinds of shelters. Some of these materials are wood, timber, straw, and bamboo used in making roofs and walls both in local and sophisticated houses. Furniture is commonly composed of wood and cloth made from plant fibers.

\section{Clothing}

Much human clothing is made from materials that come directly or indirectly from plants. Cotton is the principal plant used for clothing manufacture. Artificial textile fibers, such as rayon, are manufactured chiefly from cellulose, which is found mainly in the cell walls of plants. Linen is obtained from the flax plant.

\section{Oxygen}

Plants take in large quantities of carbon-dioxide releasing oxygen into the atmosphere during the process of photosynthesis thereby improving the quality of air, hence the oxygen in the air we breathe come from the photosynthesis of plants. Therefore as the critical part of the ecosystem, plants provide oxygen for other living organisms to survive.

\section{Medicine}

It has been estimated that about eighty percent of all the orthodox drugs originate from plants and that there are about 456 medicinal plants, which are used to manufacture more than 350 classical formulations to treat various ailments. In fact, throughout history plants have been of great importance to medicine. From the ancient times to date, people used traditional herbal medicines to treat their ailments particularly in those areas which have little or no access to modern healthcare services (Evans, 2009 and Sofowora, 1993), remember they say: ' an apple a day keeps the doctor away'.

\section{Agriculture}

Plants help in retaining the fertile topsoil not only in the forest but also in the neighboring fields (farms). The dead remains of plants when decomposed add to the fertility of the soil by releasing the important elements they contain (e.g Carbon and Nitrogen) to the soil. The forest trees transpire significant quantity of water through their leaves thus adding to the moisture in the atmosphere and bring rains. Leguminous plants have special nodules (swellings) in their root system which contain nitrogen-fixing bacteria. These functions of plants are essential for the continuity of agricultural activities.

\section{Habitat}

Plants and plant communities provide the necessary habitat (a place to live) for different animals including wildlife and many aquatic organisms. 


\section{Climate}

Regional climates are impacted by the amount and type of plant cover. Forest and marshes, for example, can cool local climates. Natural disasters, such as drought and global warming have been blamed on the destruction of forests and other critically important plant communities.

\section{Ecosystem}

The word "ecosystem" refers to a self-sustaining system whereby plants, microbes (normal flora) and animals live together supporting and interacting with each other and with the non living factors (e.g water, air, light, and temperature). Every species and factors serve an important role or purpose in the community. Plants which serve as the primary producers play the major role in any ecological system by providing the primary source of food and oxygen as well as purifying the environment for the entire system (Tanner, 2001 and Wolverton, et al., 1993). They say: "'all flesh is grass"'.

\section{Ecoremediation}

Ecoremediation is a technological process which tends to pair phytoremediation with ecosystem restoration whereby diverse indigenous and locally adapted plant species are used to clean-up (remove) contaminants such as heavy metals and petroleum hydrocarbons from contaminated soils or ground waters (phytoremediation), and at the same time reclaim derelict or deserted lands (ecosystem-restoration), for environmental sustainability and biodiversity conservation (Mcdonald, 2010 and Wolverton, et al., 1993).

\section{Erosion Control}

Plants protect the soil from erosion caused by heavy rains or wind by acting as soil stabilizers. Plants prevent or reduce soil erosion through the following ways: Roots hold the soil particles together preventing them from being washed away; Leaves and branches take much of the force of the falling rain thus checking the loosening of top soil; Trunks reduce the force of flowing waters, thus checking soil erosion; the tall trees reduce the wind velocity during storms and thus check the top soil from being blown away.

\section{Draught control}

The moisture released into the air by trees (during transpiration) stabilizes rainfall thereby decreasing the episodes of drought.

\section{Flood control}

The extensive root systems of higher plants and the networks form by many grasses (e.g Cynodon dactylon) on the ground surface reduce flooding and wind-related damage by holding soils in place, and by absorbing through their roots and canopies significant volumes of water.

\section{Air Quality}

The quality of the air can be greatly influenced by plants. Plants can stop the movement of dust and other forms of particulates and as well absorb many kinds of gaseous pollutants (GHASP, 1999 and McPherson, 1998). 
Through the intake of carbon dioxide for example, plants can lessen the anthropogenic greenhouse effect caused by burning fossil fuels like coal thereby reducing the problem of climate change and global warming.

\section{Water Quality}

Plants are extremely important to the quality of the water we use. A diverse cover of plants aids in maintaining healthy watersheds, streams, and lakes by holding soil in place, controlling stream flows, and filtering sediments from water (Tanner, 2001).

\section{Cooling the surrounding air}

Trees and other vegetation reduce atmospheric temperatures thereby cooling the surrounding environment in four ways: They trap Carbon dioxide (the major component of greenhouse gases) from the atmosphere for their photosynthesis thereby reducing greenhouse effect; Trees use solar energy (sunlight) for photosynthesis, converting the energy into food (carbohydrate) and oxygen thereby reducing the effect of the sun on sunny days; Trees provide shade, thereby cooling nearby surfaces; Trees use evapotranspiration to cool themselves and the surrounding air.

\section{Aesthetics}

Plants add to the beauty of the places that we live. It's obvious that Quiet, green areas of aesthetic repose may relate to an increase in psychological stability among urban inhabitants, and possibly to decreased violence.

\section{Recreation}

Plant communities form the basis for most important recreational activities, including hiking, sport-fishing, hunting, and ecotourism. For example the abundance of Adansonia digitata in Yankari Game Reserve supports the large number of elephant herds in the reserve and attracts both home and international tourists.

\section{Phyto-fencing}

Plants are the best tools for surrounding our houses, farms and plots of land for they proffer many advantages over cement walls or barbed steel wires. Phyto-fencing is cheaper when compared to other forms of fence and the plants help in cleansing the surrounding air by absorbing many gaseous pollutants from the atmosphere.

Bamboo when used, gives us building material and its leaves are a good fodder for cattle and goat. Phyto-fence can act as a wind breaker; in addition to protection against intruders, it serves as a shelter belt. Multipurpose and thorny plants are also preferred.

\section{Fuel}

Fuel wood is almost the only domestic fuel, not only in the rural areas but in some urbanized areas as well. Coal and natural gas are fuels used for heating and cooking. Each had their origin in plants and other organisms that lived on Earth long ago. Peat, which is formed from partially decayed plant material buried in bogs, is a common fuel. 


\section{Industrial Products}

Plants are also very important for the goods they provide. Many industrial products are made from plants such as shampoos, rubber, paper, boards, oils, gums, resins, poles, clothing, fuel products like ethanol and soy diesel, tannin (utilized by the leather industry), dyes (including mycological stains) (Abubakar et al., 2012), pharmaceuticals and botanical pesticides. The pollen of many trees and shrubs is used for honey production (beekeeping).

\section{Pesticides}

Plants secondary metabolites represent a large reservoir of chemical structures with biological activities including pesticidal (herbicidal, insecticidal, fungicidal, bactericidal, nematicidal, rodenticides and molluscicidal) potentials that can be exploited for the development of natural plant-based pesticides. Many plants produce secondary compounds that are phytotoxic to some degree (allelopathy). This phenomenon forms the basis for using plants natural products for the production of plant-based natural herbicides for controlling weeds for agricultural and other purposes. Compounds that inhibit the establishment and growth of plant pathogens are termed phytoalexins. Proof is developing that these compounds have such a role in plant disease prevention and control (Doyle, 2007).

\section{Phytopreservatives}

Several works have demonstrated in laboratory trials as well as on the field that different plant tissues such as roots, stems, leaves, seeds, fruits and flowers posses inhibitory properties against food spoilage organisms such as Aspergillu flavus, Aspergillus parasiticus (Doyle, 2007). Furthermore, natural plant-based food preservatives are generally cheaper and biologically- and environmentally-safer when compared with physical and chemical preservatives.

\section{PLANTS AND OUR ENVIRONMENT}

It is impossible to talk about an environment without plants because of their importance to the balance of nature. However, throughout human history, people have altered and often degraded their environment, though it has been taking place so gradually that its effects have not been drastically felt. The levels of greenhouse gases have increased dramatically over the last century. This increase is attributed to increase in deforestation and fossil fuel combustion. Increased levels of these gases are thought to be the primary cause of environmental degradation. Trees and other vegetation directly remove many gaseous and particulate pollutants from the air, and indirectly reduce air pollution as well thereby reducing the greenhouse effect. A single tree with a trunk circumference of 30 inches removes: 200 pounds $(91 \mathrm{Kg})$ of carbon dioxide, 1.1 pounds (499 g) of ozone, 2 pounds (907 g) of sulfur dioxide 2 pounds $(907 \mathrm{~g})$ of particulates and 2 pounds $(907 \mathrm{~g})$ of nitrogen oxides every year as reported by GHASP (1999). Further studies conducted have found plants to be one of the most efficient and effective mechanisms for cleaning the air of contaminants, and for supplying vital oxygen and that three matured shade trees planted on the southeast and southwest sides of a house can reduce the temperatures on a sunny day by up to $50 \%$. For example, a single large tree can transpire up to 100 gallons $(400$ l) of water a day, producing a cooling effect similar to that of five average air conditioners running for 20 hours (GHASP, 1999). Urban 
parks, trees along streets, and greenbelts apart from cleansing the surrounding air of gaseous pollutants, are also highly effective as light and noise barriers.

\section{PLANTS IN PERIL}

Despite the immeasurable importance of plants to humanity, they are disappearing at alarming rates. The reasons for this loss are many and include bush burning, over-grazing, deforestation, and developmental activities such as road construction, urbanization, industrialization, and introduction of exotic species. We are destroying our plants at a frightening rate that many of them are on the way to extinction. In Nigeria for example, about 431 species of plants are endangered; 45 species are categorized as rare; and 20 species are vulnerable; while 305 species of plants are endemic, (Gani, 2011).

\section{THE WAY FORWARD}

Looking at the enormous benefits of plants to the existence of life on earth, it has become quite imperative to ensure effective conservation of these vital resources for the benefit of both present and future generations before they are lost to the rapidly changing environment through the following ways:

\section{1. Through Awareness Campaigns:}

Awareness of the general public of the need to conserve our plants can be created through the use of media agencies and seminars. In the process, direct campaign should be launched against deforestation, indiscriminate and unsustainable exploitation of plants, uncontrolled bush burning and over grazing.

\section{2. In Situ and ex situ Conservation techniques}

In situ conservation involves the use of National Parks, Game Reserves and Forest Reserves which are established by law for the conservation of threatened, endangered, rare and common plant species in their natural habitat. Ex situ conservation techniques for the conservation of threatened, endangered and rare plant species, involve the use of botanical gardens, arboreta and in vitro technique. In this strategy, these plant species are grown outside their natural habitats and can later be reintroduced into their original habitats for restocking purpose.

\section{3. Involvement of the People in Conservation Programs}

Involvement of the local people particularly those living close to the conservation areas guarantee the success of the conservation project and programs. When the local people are not involved their actions tend to conflict with the goals of the conservation program.

\section{4. Creating Job Opportunities for Youths}

Indiscriminate utilization of Natural Resources, such as illegal logging and poaching especially for economic reasons are reduced if not completely checked through the creation of alternative and gainful employment particularly for those living in or around the support zone communities of protected areas. 


\section{5. Appropriate Land-Use Policies and laws}

Rational land use policies should be formulated taking into consideration the protection of the country's flora. Laws are used to establish in situ conservation areas such as National Parks and Game Reserves. They are also to control indiscriminate use and destruction of plants. The laws prescribe punishment for defaulters and therefore help to check abuses.

\section{6. Involvement of Public Liability Companies and Corporations}

Public liability companies and corporations have a role to play in the conservation of the country's flora whereby companies and corporations are by law expected to use a certain percentage of their profit to support and promote conservation projects and institutions. In Africa such companies should include: Banks, manufacturing industries, construction companies, GSM networks.

\section{7. Monitoring agencies}

Monitoring agencies may be governmental or non-governmental. Their functions are to implement and supervise all the national conservation strategies as well as to monitor and evaluate the status of plant resources from time to time and assist in policy formulation and implementation.

\section{8. Other ways for Achieving Environmental Sustainability}

Some other ways for reducing environmental degradation and achieving sustainable development include among others, the use of alternative energy sources other than fossil fuel to reduce anthropogenic emissions, Promoting mass transportation and bicycling to reduce emissions, Appropriate town planning to include green spaces in strategic places especially in urban settlements, Sustainable agriculture, use of greenbelts around industries, Planting trees along our streets, Screen-to-nature technique, Proper management of wastes, environmental sanitation and aforestation.

\section{CONCLUSION}

The direct and indirect benefits of trees and other vegetation on the quality of life on earth cannot be over emphasized. Although there is wide scientific consensus that anthropogenic emissions must be reduced, planting and protecting large and fast growing trees is the easiest and cheapest biotechnological method for conserving these vital renewable natural resources, reducing environmental degradation and achieving sustainable development.

\section{Recommendation}

- There is need for collaboration among global and regional research and development organizations to exchange up-to-date information on modern conservation techniques and help in updating and implementing appropriate environmental policies.

- Maintain, at both global and regional levels, an up-to-date census of the different plant species, so that it will always be obvious which are well protected in nature, and which are rare and endangered.

- In vitro production of planting materials through Biotechnological tools for afforestation 
programs in desertification-prone areas of the world

- Devote special attention to the conservation of medicinal plants.

- Establishing, enforcing and maintaining cattle routes and grazing reserves throughout the country.

\section{References}

[1] Abubakar S., Usman A. B., Etim V., Nnadi O., C. Alaku, Indian Journal of Innovations and Devevelopment 1(9) (2012) 687-690.

[2] Doyle M. E., Microbial food spoilage- losses and control strategies, Food Research Institute Briefings: 16 (2007).

[3] Duke S. S. (1990). Natural pesticides from plants, pp. 511-517 In: Janick J and JE Simon (eds.), Advances in new crops. Timber Press, Portland,

[4] Evans W. C. (2009). Trease and Evans pharmacognocy, $16^{\text {th }}$ ed, Saunders Elsevier London, pp. 603.

[5] Gani A. M., Nig. J. of Bot. 24(1) (2011) 5-16.

[6] GHASP (1999). Galveston-Houston Association for Smog Prevention, trees and our air, The Role of Trees and Other Vegetation in Houston-Area Air Pollution Houston, Texas, www.neosoft.com/ ghasp,

[7] Lawal D. (2013). Synergisism of medicinal plants on Aeromonas hydrophyla and Salmonella, first edition, Lambert academic publishing, Deutschland, Germany, pp. 113.

[8] Mcdonald T., Eco. Society of Australia 11(1) (2010) 2-3.

[9] Oparaeke A. M., Dike M. C., C. I. Amatobi, Plant Protect. Sci. 41(1) (2004) 14-20.

[10] Sofowara A., J. of Ethnopharmacology 38 (1993) 209-214.

[11] Tanner C. C., Water Science and Technology 44(11) (2011) 9-17.

[12] Wolverton B. C., J. D. Wolverton, Journal of the Mississipi Academy of Sciences 38(2) (1993) 11-15. 